\title{
Sensitivity of the quasi-biennial oscillation to $\mathrm{CO}_{2}$ doubling
}

\author{
Marco A. Giorgetta and Martin C. Doege \\ Max Planck Institute for Meteorology, Hamburg, Germany \\ Received 11 November 2004; revised 1 March 2005; accepted 9 March 2005; published 16 April 2005.
}

[1] The quasi-biennial oscillation (QBO) is a major oscillation with a characteristic period of 28 months that influences substantially the stratospheric circulation and chemistry. This exploratory study investigates its possible change by direct simulation of the $\mathrm{QBO}$ in a doubled $\mathrm{CO}_{2}$ climate for a range of gravity wave sources. It is found that a QBO spin-up is likely. In the most extreme case the period is nearly halved. Important accelerating factors are the decreased tropical upwelling and increased gravity wave drag, while increased filtering of eastward gravity waves in the upper tropical troposphere acts as a decelerating factor. Citation: Giorgetta, M. A., and M. C. Doege (2005), Sensitivity of the quasi-biennial oscillation to $\mathrm{CO}_{2}$ doubling, Geophys. Res. Lett., 32, L08701, doi:10.1029/2004GL021971.

\section{Introduction}

[2] The QBO consists of a sequence of eastward (or westerly) and westward (or easterly) jets of about 15 and $30 \mathrm{~m} / \mathrm{s}$, respectively, which propagate from their formation level near $40 \mathrm{~km}$ altitude to their dissipation level near $18 \mathrm{~km}$ altitude [Baldwin et al., 2001], and its secondary meridional circulation creates significant signals in ozone [Randel and $W u, 1996]$, methane [Randel et al., 1998] and other chemicals. The latitudinal half width of the jets is typically $12^{\circ}$ latitude. The secondary meridional circulation of the QBO extends to $30^{\circ}$ latitude and the effects on chemicals are observed also in the extratropics. The QBO is embedded in the upwelling region of the Brewer-Dobson circulation against which the QBO jets propagate downwards. This propagation is driven by the interaction of the jets with upward propagating equatorial waves. There is now substantial evidence that a broad spectrum of waves contributes to the QBO forcing [Bergman and Salby, 1994; Gray and Pyle, 1989; Takahashi, 1999; Giorgetta et al., 2002]. Tropical deep convection and convective systems play a major role in the excitation of this wave spectrum [Horinouchi et al., 2003; Alexander and Pfister, 1995].

[3] Regular observations of the QBO started in 1953. Until today 21 complete cycles have been observed. Generally the QBO can be characterized by monthly mean zonal wind profiles at equatorial stations. The length of QBO cycles at $20 \mathrm{hPa}$, as observed at Canton Island (Jan. 1953 to Aug. 1967), Gan/Maledives (Sept. 1967 to Dec. 1975) and Singapore (Jan. 1976 onwards) [Labitzke et al., 2002], has varied within a range of 19 months (starting in March 1959) to 34 months (starting in Sept. 1998) with an average of 28 months. Naujokat [1986] has found the same average in an earlier analysis including 14 cycles. In general

Copyright 2005 by the American Geophysical Union. 0094-8276/05/2004GL021971\$05.00 the variability of cycle lengths is considerable and it is not possible to determine any significant trend since the mid 1950s. Probably this has been the case since at least the early 1900's [Hamilton and Garcia, 1984; Teitelbaum et al., 1995]. Whether the QBO will change its characteristics in a future climate with a substantially increased $\mathrm{CO}_{2}$ abundance and presumably higher tropical sea surface temperatures is the subject of this study.

[4] Climate change predictions, as for example reported and coordinated by the International Panel on Climate Change (IPCC), have been performed mostly to investigate changes in the tropospheric climate, and often the predicted changes have been discussed for $\mathrm{CO}_{2}$ doubling, e.g. as climate sensitivity of global mean surface temperature. Among the various possible influences that climate change can induce on natural variability, the sensitivity of the QBO to substantially increased $\mathrm{CO}_{2}$ abundance has not been studied so far, because of the known difficulties in the spontaneous simulation of the $\mathrm{QBO}$ with general circulation models of the atmosphere, only recently overcome. Making use of the current availability of a model that does spontaneously simulate the QBO [Giorgetta et al., 2002], we intend to use it to explore how the simulated QBO responds to a $\mathrm{CO}_{2}$ doubling.

[5] The sensitivity of the QBO to modified forcings has been studied before. The dependence of the QBO period on the wave driving, as theoretically expected, has been demonstrated in mechanistic two- and three-dimensional models, where the total wave forcing is controlled externally [Gray and Pyle, 1989; Dunkerton, 1985; Takahashi and Boville, 1992]. Further, it has been demonstrated that the QBO in the SKYHI GCM, though with approximately annual period, has a strong sensitivity to changes in the intensity of the tropical convection which is induced by lowering or rising the tropical sea surface temperature (SST) by $2.5^{\circ} \mathrm{C}$ near the equator [Hamilton et al., 2001].

[6] The increase of $\mathrm{CO}_{2}$ levels in our simulations directly strengthens the longwave radiative cooling in the middle atmosphere with two possible implications for the QBO. Firstly, the mean meridional circulation in the stratosphere, which is driven by planetary waves and gravity waves in the extratropics will respond to changes in the balance of radiative and dynamical forcing. This issue is discussed, for example, by Fels [1985]. The possible future change in this balance is a subject of current research [Austin et al., 2003]. Resulting modifications of the climatological upwelling profile in the tropical stratosphere would have consequences for the effective vertical propagation of the jets of the QBO. Secondly, higher $\mathrm{CO}_{2}$ levels would strengthen the radiative damping of waves in the stratosphere. For the given reasons, the period and possibly other characteristics of the QBO may change in the future. Notably this includes the possibility of a transition of the 
QBO to an episodic oscillation, to a stationary state, or to a complete breakdown.

\section{The MAECHAM5 General Circulation Model}

[7] The GCM employed is the ECHAM5 GCM [Roeckner et al., 2003] in its middle atmosphere configuration (MAECHAM5) at a horizontal spectral resolution of T42 (ca. $2.8^{\circ}$ in longitude and latitude) with 90 layers resolving the atmosphere up to $0.01 \mathrm{hPa}(\mathrm{ca} .80 \mathrm{~km})$. This configuration allows the simulation of a realistic QBO [Giorgetta et al., 2002, Figure 1].

[8] The MAECHAM5 GCM includes a parameterization for convection [Tiedtke, 1989; Nordeng, 1996], which is important for the excitation of resolved equatorial waves, and a gravity wave drag parameterization for a spectrum of sub grid-scale gravity waves [Hines, 1997; Manzini et al., 1997]. Since there is not yet an established method to infer the gravity wave source spectrum from the resolved circulation, it is necessary to specify the sources externally. Here we use space and time constant gravity wave parameters as in case UNI2 of Charron and Manzini [2002]. Therefore, an isotropic spectrum with a root mean square gravity wave wind speed of $1 \mathrm{~m} / \mathrm{s}$ and effective horizontal wave number $\mathrm{K}^{*}=2 \pi(126 \mathrm{~km})^{-1}$ is launched from the lower troposphere, at about $600 \mathrm{hPa}$. This choice of parameters has been determined for the current climate in order to obtain a realistic high latitude circulation in the middle atmosphere. For future climates, however, the gravity wave excitation might change, which would require modifications of the specified sources.

\section{Experimental Design}

[9] In the following experiments, the current climate is characterized by a uniform $\mathrm{CO}_{2}$ mixing ratio of 348 ppmv, climatological SST and sea ice conditions for the AMIP2 period 1978 to 1994 [Gates et al., 1999], and gravity wave parameters for the source spectrum as explained above. The assumed future climate is characterized by a doubled $\mathrm{CO}_{2}$ mixing ratio of $696 \mathrm{ppmv}$ and SST and sea ice conditions constructed from the AMIP2 data set and difference fields derived from a set of coupled atmosphere ocean experiments, such that $\mathrm{SST}_{2 \times \mathrm{xO} 2}=\mathrm{SST}_{\mathrm{AMIP} 2}+\mathrm{dSST}_{1 \times \mathrm{xO} 2} \rightarrow 2 \times \mathrm{xO} 2$, and a modified source strength of the gravity wave spectrum.

[10] The SST difference field is derived from three experiments with the coupled atmosphere ocean ECHAM5MPIOM model system based on the tropospheric version of ECHAM5. The experiments are (1) a multi-decadal control experiment with 348 ppmv $\mathrm{CO}_{2}$, (2) a transient experiment with an annual $\mathrm{CO}_{2}$ increase of $1 \%$ started from the coupled control experiment, and (3) a subsequent stabilization experiment, where the $\mathrm{CO}_{2}$ mixing ratio is fixed at 696 ppmv. The difference $\mathrm{dSST}_{1 \times \mathrm{xO} 2} \rightarrow 2 \times \mathrm{xO} 2$ is then constructed from the initial 20 years of the stabilization experiment and the climatology of the coupled control experiment. This construction avoids systematic biases in the SST fields related rather to coupling deficiencies than to the $\mathrm{CO}_{2}$ increase. Note also that the constructed data set is representative for the years around $\mathrm{CO}_{2}$ doubling, and not for conditions in an equilibrated climate at doubled $\mathrm{CO}_{2}$ mixing ratio. The resulting tropical SSTs in the $2 \mathrm{xCO}_{2}$ climate are increased by about $2^{\circ} \mathrm{C}$. The northern subtropics and mid-latitudes show SSTs increased by 1.5 to $2^{\circ} \mathrm{C}$, while the southern extratropics show much smaller changes.

[11] Modifications of the source spectrum of the gravity waves for the $2 \mathrm{xCO}_{2}$ climate must be prescribed for the reasons given above. For simplicity only one parameter is varied here, the root mean square wind (rms-wind) of the gravity wave field at the launch level. The characteristic wavelength and the launch level are kept unchanged. Also the assumption on the spatial and temporal homogeneity and isotropy of the source spectrum are retained. Due to the uncertainty in the choice of a future rms-wind three different parameter values are used below.

[12] The experimental design of this study includes a 30 -year reference simulation (CONTROL) for the current climate and three 20-year experiments for the $2 \mathrm{xCO}_{2}$ climate (DCO2, DP10, DP20), which differ in the specified rms-wind of the gravity wave source spectrum. In DCO2, the rms-wind is set to $1 \mathrm{~m} / \mathrm{s}$, as in CONTROL. In DP10 and DP20, the rms-wind is increased by $10 \%$ and $20 \%$, respectively. A strengthening of the tropospheric gravity wave sources is anticipated due to the increase of the intramonthly variance of precipitation, which is indeed found in DCO2 compared to CONTROL. The annual and zonal mean of intra-monthly variance in precipitation is increased by factors of 1.37 in $45^{\circ} \mathrm{N}-15^{\circ} \mathrm{N}, 1.69$ in $15^{\circ} \mathrm{N}-15^{\circ} \mathrm{S}$ and 1.12 in $15^{\circ} \mathrm{S}-45^{\circ} \mathrm{S}$, corresponding to an increase of the respective standard deviations by a factor of $1.17,1.30$, and 1.06 , respectively. These values motivated the choice of increased rms-wind values in DP10 and DP20.

\section{Results}

[13] In these experiments we find an acceleration of the QBO with average periods of 26, 22, and 17 months in DCO2, DP10 and DP20, respectively, instead of 29 months in CONTROL. The decrease in the QBO periods in DP10 and DP20 are statistically significant compared to CONTROL, while that in DCO2 is not.

[14] Figure 1 displays the average structure of the simulated QBOs at onset of equatorial zonal mean westerlies at $20 \mathrm{hPa}$. Here, the annual variation of the zonal mean zonal wind has been subtracted beforehand. The annual means are retained, so that the composites still show the typical asymmetry between the westerly and easterly phases. The average period and the propagation rate are nearly identical in CONTROL and DCO2, though there are differences in the structure. The strongest change is found in the duration of the westerly phase, which lasts up to 3 months longer between $10 \mathrm{hPa}$ and $40 \mathrm{hPa}$, while the easterly phase is shorter and weaker. Below $40 \mathrm{hPa}$, the westerly phase of DCO2 is weaker and stops slightly higher. Tropospheric westerlies are visible to higher levels in DCO2. In DP10, the descent of the phases evolves approximately 6 months faster than in CONTROL. The maximum of the westerly phase exceeds $20 \mathrm{~m} / \mathrm{s}$, which is about $5 \mathrm{~m} / \mathrm{s}$ higher than in CONTROL or DCO2. At the same time the easterly phase is about $5 \mathrm{~m} / \mathrm{s}$ weaker than in CONTROL. Changes below $60 \mathrm{hPa}$ are negligible compared to DCO2. In DP20, the oscillation is strongly accelerated and its period is rather annual than biennial. The maximum of the westerlies is similar to that in DP10, but the vertical extent of westerlies exceeding $20 \mathrm{~m} / \mathrm{s}$ or $15 \mathrm{~m} / \mathrm{s}$ is larger. Westerlies are strengthened also below $30 \mathrm{hPa}$. The onset and decay of 

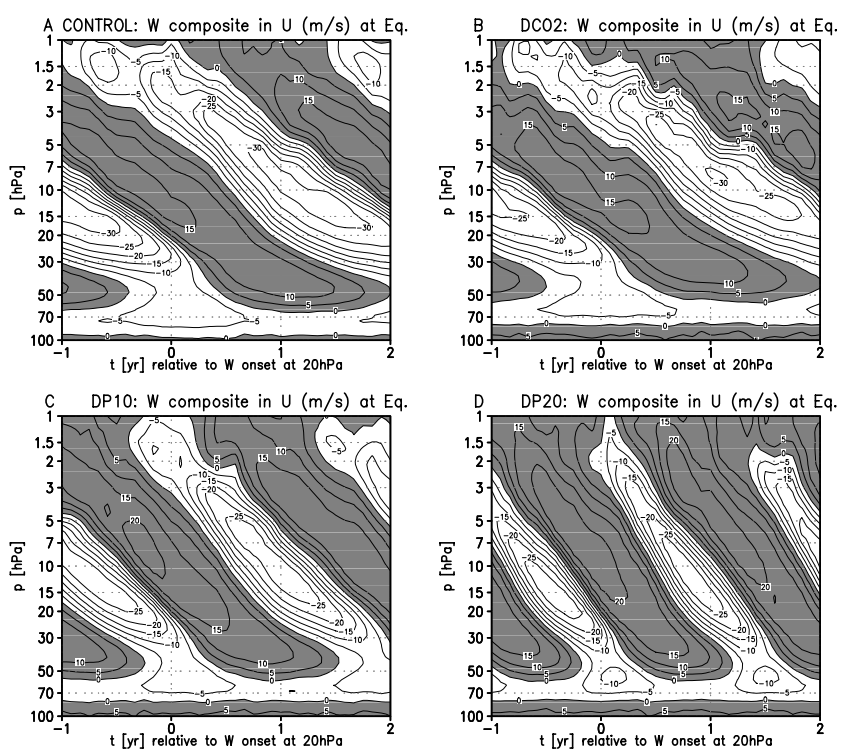

Figure 1. $\mathrm{QBO}$ composites in $\mathrm{U}$ in $\mathrm{m} / \mathrm{s}$ for onset of zonal mean westerlies at the equator at $20 \mathrm{hPa}$ in (a) CONTROL, (b) DCO2, (c) DP10 and (d) DP20.

easterlies is strongly accelerated, much more than for the westerlies. Secondary maxima of easterlies between $50 \mathrm{hPa}$ and $70 \mathrm{hPa}$ are stronger.

[15] Changes in the QBO structure must be interpreted with respect to the changes in the tropical upwelling and its effect on momentum advection, and the changes of tendencies by resolved wave mean-flow interaction, and parameterized gravity wave drag. It is found that the annual zonal mean upwelling averaged between $20^{\circ} \mathrm{N}$ and $20^{\circ} \mathrm{S}$ is decreased in DCO2, DP10 and DP20 by 0.1 to $0.2 \mathrm{~mm} / \mathrm{s}$ between 50 and $3 \mathrm{hPa}$ compared to CONTROL. The broad latitudinal average has been chosen in order to remove effects of the secondary meridional circulations of the QBOs on the diagnosed tropical upwelling. The upwelling is nearly identical in DCO2, DP10 and DP20, showing that the tropical upwelling, as defined here, is not sensitive to the specified changes in gravity wave sources. Hence the decrease in the tropical upwelling is the combined effect of the imposed changes in $\mathrm{CO}_{2}$, SST and ice. The largescale change in tropical upwelling would accelerate the $\mathrm{QBO}$, if nothing else changes.

[16] Composites of tendencies related to resolved wave mean-flow interaction (RW, green), parameterized gravity wave drag (GW, red), advection (blue) and their sum (black) are compiled in Figure 2 for all four experiments (from top to bottom), for the westerly phase (left) and the easterly phase (right). The average QBO phases are shown (dashed, in units of $10 \mathrm{~m} / \mathrm{s}$ ) to indicate the position of the shear layers.

[17] Comparing DCO2 with CONTROL we find that the forcing is $20 \%$ stronger in the westerly shear, although the RW forcing is nearly identical and the GW forcing is weaker. This is overcompensated by the advection, which has a local maximum at the level of the forcing maximum, differently to CONTROL, where advection plays no role. The RW profile shows a secondary maximum near $50 \mathrm{hPa}$, which is clearly amplified in DCO2. Interestingly the zonal wind shear is nearly zero in this layer so that increased radiative damping is a candidate for the intensified wave dissipation occurring near $50 \mathrm{hPa}$. The decrease of the $\mathrm{GW}$ forcing at $20 \mathrm{hPa}$ by $30 \%$ can only be explained by the differences in the wind profiles between the source level at $600 \mathrm{hPa}$ and the level of interest at $20 \mathrm{hPa}$. It is found that the increase of equatorial westerlies in the upper troposphere and tropopause region, between $300 \mathrm{hPa}$ and $70 \mathrm{hPa}$, cause additional filtering of eastward waves so that less gravity wave drag occurs in the positive shear layer at $20 \mathrm{hPa}$, although the gravity wave sources are unchanged and the shear at $20 \mathrm{hPa}$ is nearly identical in both experiments. The forcing of the easterly phase is increased by ca. $65 \%$. This is explained entirely by the significant decrease of the advective westerly tendency. The RW and GW forcings change little.

[18] The forcings in DP10 show the effects of the $10 \%$ increase in the gravity wave sources with respect to those in CONTROL and DCO2. The forcing in the westerly shear
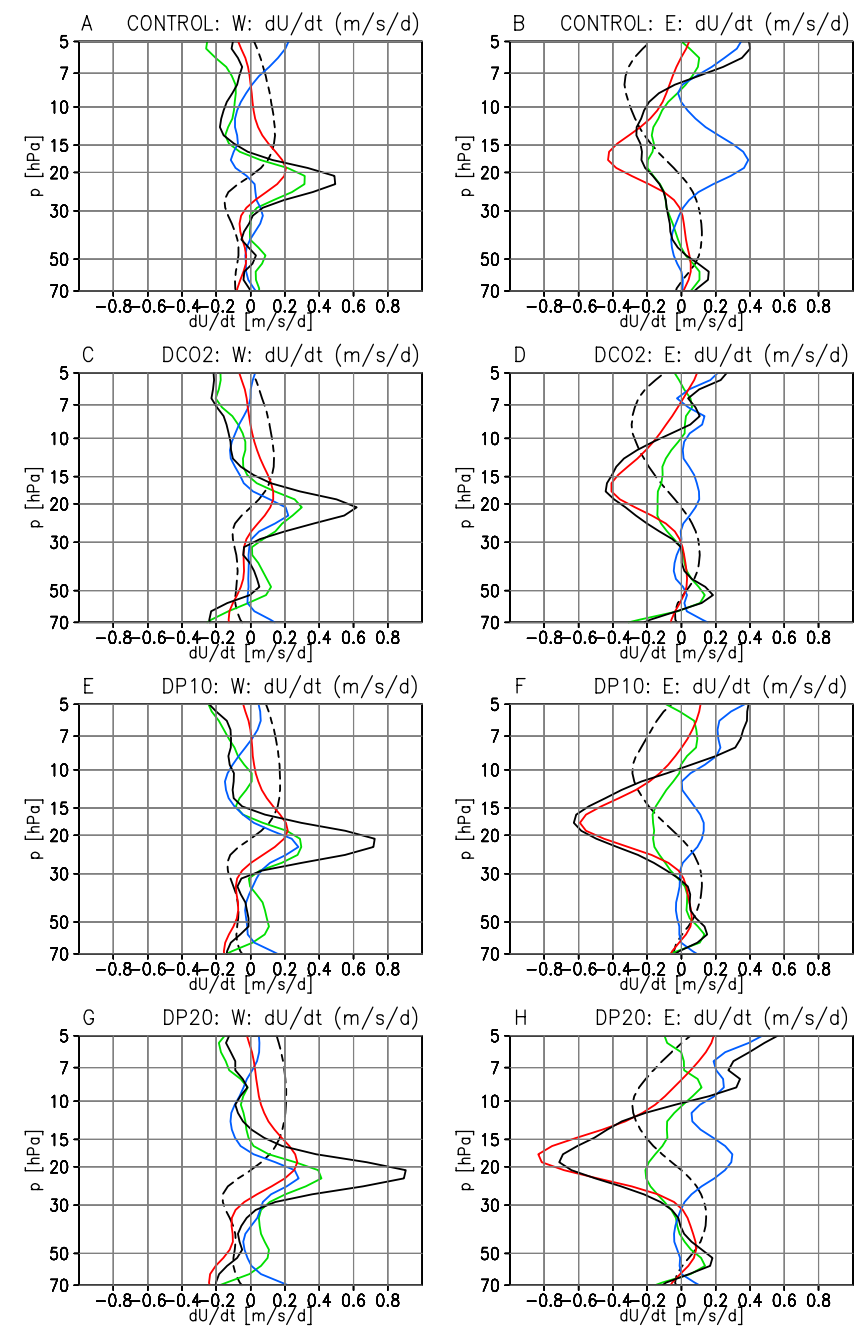

Figure 2. Tendencies $\mathrm{dU} / \mathrm{dt}$ in $\mathrm{m} / \mathrm{s} /$ day by resolved wave mean-flow interaction (green), parameterized gravity wave drag (red) and advection (blue), and their sum (black) in the experiments CONTROL, DCO2, DP10 and DP20 (top to bottom) for (left) the westerly phase and (right) the easterly phase. The QBO phase is shown as dashed line in units of $10 \mathrm{~m} / \mathrm{s}$. 
zone is about $20 \%$ stronger than in DCO2, which is explained by increased GW forcing, which is comparable to the GW forcing in CONTROL with the weaker sources, and the stronger advective tendency due to the stronger westerly jet above. In the easterly shear layer, the forcing increases by about $50 \%$ due to the stronger GW forcing.

[19] In DP20, the forcing in the westerly shear layer is again $25 \%$ stronger than in DP10, explained firstly by a $40 \%$ increase in RW forcing and a $25 \%$ increase in the GW forcing. Also the easterly forcing is increased by ca. $15 \%$, mostly explained by the stronger $\mathrm{GW}$ forcing compared to CP10.

[20] Common features of the climate change experiments are the increase of the westerly advective forcing in the westerly shear and the decrease of the westerly advective forcing in the easterly shear layer, which is consistent with the reduction of the broad scale upwelling. A second feature is the increased filtering of eastward gravity waves between the level of the gravity wave sources and the westerly shear layer. The resulting decrease in gravity wave drag in DCO2 is then compensated by the $10 \%$ increase of the gravity wave sources in DP10 and intensified more in DP20. The filtering in the upper troposphere does not change for the westward gravity waves so that the $\mathrm{GW}$ forcing is similar in CONTROL and DCO2, but intensified in DP10 and more in DP20. Further an intensification of the RW forcing occurs commonly at $50 \mathrm{hPa}$ below the westerly shear layer, without an immediate effect on the QBO propagation. This wave mean-flow interaction occurs in a layer with weak zonal wind and zonal wind shear.

\section{Conclusions}

[21] We used a GCM that simulates a realistic QBO in the current climate for an exploratory study of the possible changes of the $\mathrm{QBO}$ in future $2 \mathrm{xCO}_{2}$ climate conditions. The experiments show a spin-up of the QBO from the current average period of 29 months to a range of periods of 26 to 17 months, depending on the assumed intensification of gravity wave sources that are varied by 0 to $20 \%$. The QBO spin-up found here results mainly from two effects: (1) the reduced tropical upwelling, effective both for westerly and easterly jets; and (2) imposed changes in the gravity wave sources, intensifying the forcing of easterly and westerly jets. Increased filtering of the eastward gravity waves in the upper tropical troposphere reduces the gravity wave drag in the westerly shear layer and hence opposes the spin-up. The resolved wave forcing changes little in the QBO shear layers, except in the westerly shear layer of the experiment with the strongest increase in the gravity wave source strength. Based on this work, changes of the QBO in a $2 \mathrm{xCO}_{2}$ climate are expected, though more work will be necessary due to the limitations of this study and to further detail and confirm the results obtained here. Eventually it will be necessary to simulate gravity wave sources related to convection. Analogous to tropospheric climate change studies, experiments will have to include a coupled atmosphere ocean system.
[22] Acknowledgments. We thank M. Botzet, M. Esch and U. Schulzweida for their help, and E. Manzini, E. Roeckner, R. Garcia, G. Brasseur and two anonymous reviewers for their suggestions. BMBF/ KODYACS and BMBF/DEKLIM funded part of this work.

\section{References}

Alexander, J., and L. Pfister (1995), Gravity wave momentum flux in the lower stratosphere over convection, Geophys. Res. Lett., 22, 2029-2032. Austin, J., et al. (2003), Uncertainties and assessments of chemistry-climate models of the stratosphere, Atmos. Chem. Phys., 3, 1-27.

Baldwin, M. P., et al. (2001), The quasi-biennial oscillation, Rev. Geophys., $39,179-229$.

Bergman, J. W., and M. L. Salby (1994), Equatorial wave activity derived from fluctuations in observed convection, J. Atmos. Sci., 51, 3791-3806.

Charron, M., and E. Manzini (2002), Gravity waves from frtons: Parameterization and middle atmosphere response in a general circulation model, J. Atmos. Sci., 59, 923-941.

Dunkerton, T. J. (1985), A two-dimensional model of the quasi-biennial oscillation, J. Atmos. Sci., 42, 1151-1160.

Fels, S. B. (1985), Radiative-dynamical interactions in the middle atmosphere, Adv. Geophys., 28A, 277-300.

Gates, L., et al. (1999), An overview of the results of the Atmospheric Model Intercomparison Project (AMIP), Bull. Am. Meteorol. Soc., 80, $29-55$.

Giorgetta, M. A., E. Manzini, and E. Roeckner (2002), Forcing of the quasibiennial oscillation from a broad spectrum of atmospheric waves, Geophys. Res. Lett., 29(8), 1245, doi:10.1029/2002GL014756.

Gray, L. J., and J. A. Pyle (1989), A two-dimensional model of the quasibiennial oscillation in ozone, J. Atmos. Sci., 46, 203-220.

Hamilton, K., and R. R. Garcia (1984), Long-period variatons in the solar semidiurnal atmospheric tide, J. Geophys. Res., 89, 11,705-11,710.

Hamilton, K., R. J. Wilson, and R. H. Hemler (2001), Spontaneous stratospheric QBO-like oscillations simulated by the GFDL SKYHI general circulation model, J. Atmos. Sci., 58, 3271-3292.

Hines, C. O. (1997), Doppler-spread parameterization of gravity wave momentum deposition in the middle atmosphere, 2, Broad and quasimonochromatic spectra, and implementation, J. Atmos. Sol. Terr. Phys., $59,387-400$.

Horinouchi, T., et al. (2003), Tropical cumulus convection and upwardpropagating waves in middle-atmospheric GCMs, J. Atmos. Sci., 60, $2765-2782$.

Labitzke, K., et al. (2002), The Berlin Stratospheric Data Series [CD-ROM], Meteorol. Inst., Frei Univ. Berlin, Berlin, Germany.

Manzini, E., N. A. McFarlane, and C. McLandress (1997), Impact of the Doppler spread parameterization on the simulation of the middle atmosphere circulation using the MA/ECHAM4 general circulation model, J. Geophys. Res., 102, 25,751-25,762.

Naujokat, B. (1986), An update of the observed quasi-biennial oscillation of the stratospheric winds over the tropics, J. Atmos. Sci., 43, 1873-1877. Nordeng, T. E. (1996), Extended versions of the convective parametrization scheme at ECMWF and their impact on the mean and transient activity of the model in the tropics, Tech. Memo 206, Res. Dep., Eur. Cent. for Medium-Range Weather Forecasting, Reading, UK.

Randel, W. J., and F. Wu (1996), Isolation of the ozone QBO in SAGE II data by singular decomposition, J. Atmos. Sci., 53, 2546-2559.

Randel, W. J., F. Wu, J. M. Russel III, A. Roche, and J. Waters (1998), Seasonal cycles and QBO variations in stratospheric $\mathrm{CH}_{4}$ and $\mathrm{H}_{2} \mathrm{O}$ observed in UARS HALOE data, J. Atmos. Sci., 55, 163-185.

Roeckner, E. et al. (2003), The atmospheric general circulation model ECHAM 5. part I: Model description, MPI-Rep. 349, 127 pp, MaxPlanck-Inst., Hamburg, Germany.

Takahashi, M. (1999), Simulation of the quasi-biennial oscillation in a general circulation model, Geophys. Res. Lett., 26, 1307-1310.

Takahashi, M., and B. A. Boville (1992), A three-dimensional simulation of the equatorial quasi-biennial oscillation, J. Atmos. Sci., 49, 1020-1035.

Teitelbaum, H., F. Vial, and P. Bauer (1995), The stratospheric quasibiennial oscillation observed in the semi-diurnal ground pressure data, Ann. Geophys., 13, 740-744.

Tiedtke, M. (1989), A comprehensive mass flux scheme for cumulus parameterization in large-scale models, Mon. Weather Rev., 117, 1779-1800.

M. C. Doege and M. A. Giorgetta, Max Planck Inst. for Meteorol., Bundesstr. 53, D-20146 Hamburg, Germany. (giorgetta@dkrz.de) 